\title{
Quantifying the effect of kinetic uncertainties on NO predictions at engine-relevant pressures in premixed methane-air flames
}

\author{
Antoine Durocher* \\ ASME Student Member \\ Department of Mechanical Engineering, \\ McGill University, \\ Montréal, Qc H3A 0C3, Canada \\ Jeffrey M. Bergthorson \\ Fellow ASME \\ Department of Mechanical Engineering, \\ McGill University, \\ Montréal, Qc H3A 0C3, Canada \\ email: jeff.bergthorson@mcgill.ca
}

Gilles Bourque

Fellow ASME

Combustion Key Expert

Siemens Canada Limited,

email: antoine.durocher@mail.mcgill.ca Department of Mechanical Engineering,

McGill University,

Montréal, Qc H3A 0C3, Canada

emails: gilles.bourque@mcgill.ca,

gilles.bourque@siemens.com

\begin{abstract}
Accurate and robust thermochemical models are required to identify future low- $N O_{x}$ technologies that can meet the increasingly stringent emissions regulations in the gas turbine industry. These mechanisms are generally optimized and validated for specific ranges of operating conditions, which result in an abundance of models offering accurate nominal solutions over different parameter ranges. At atmospheric conditions, and for methane combustion, a relatively good agreement between models and experiments is currently observed. At engine-relevant pressures, however, a large variability in predictions is obtained as the models are often used outside their validation region. The high levels of uncertainty found in chemical kinetic rates enable such discrepancies between models, even as the reactions are within recommended rate values. The current work investigates the effect of such kinetic uncertainties in NO predictions by propagating the uncertainties of 30 reactions, that are both uncertain and

grid approach is used to obtain accurate surrogate models to quantify NO prediction intervals at various pressures. The forward analysis is carried up to $32 \mathrm{~atm}$ to quantify the uncertainty in emissions predictions to pressures relevant to the gas turbine community, which reveals that the NO prediction uncertainty decreases with pressure. After performing a Reaction Pathway Analysis, this reduction is attributed to the decreasing contribution of the prompt-NO pathway to total emissions, as the peak $\mathrm{CH}$ concentration and the $\mathrm{CH}$ layer thickness decrease with pressure. In the studied lean condition, the contribution of the pressure-dependent $\mathrm{N}_{2} \mathrm{O}$ production route increases rapidly up to $10 \mathrm{~atm}$ before stabilizing towards engine-relevant pressures. The uncertain prediction ranges provide insight into the accuracy and precision of simulations at high pressures and warrant further research to constrain the uncertainty limits of kinetic rates to capture NO concentrations with confidence in early design phases.
\end{abstract} important to NO formation, through the combustion model at engine-relevant pressures. Understanding the uncertainty sources in model predictions and their effect on emissions at these pressures is key in developing accurate thermochemical models to design future combustion chambers with any confidence. Lean adiabatic, freely-propagating, laminar flames are therefore chosen to study the effect of parametric kinetic uncertainties. A non-intrusive, level 2, nested sparse-

*Corresponding author. Email: antoine.durocher@mail.mcgill.ca

\section{Introduction}

Any combustion of fuels with air will produce nitrogen oxides $\left(\mathrm{NO}_{x}\right)$, which negatively affect human health and the environment. To reduce their contribution to worldwide emissions, and to meet the increasingly stringent regulations, engine manufacturers are actively developing new low- $\mathrm{NO}_{x}$ technologies and combustor architectures [1]. With growing computational power, the industry is steadily increasing the 
number and complexity of simulations performed to identify optimal configurations. High accuracy, both in modelling and predictions, therefore becomes increasingly important to distinguish promising designs [2].

The development of thermochemical mechanisms has followed this ideology for the last few decades, growing in the number of species and the number of reactions, to capture increasingly complex combustion phenomena [3]. From the well-known GRI mechanism [4] to hierarchically built models [5], these detailed mechanisms each have unique sets of reactions, species, and reaction rates optimized and validated towards specific applications. However, taken outside of their validation range, they can exhibit large discrepancies in predictions. For gas turbine applications, recent highpressure measurements have shown that, although a reasonable agreement between a selection of mechanisms can be obtained at lower pressures, large discrepancies were observed in predictions of reference flame speeds and burning rates [6,7] and NO concentrations [8]. Furthermore, understanding the effect of pressure on $\mathrm{NO}_{x}$ formation has been identified as one of the key challenges to develop accurate nitrogen chemistry [9], and is especially important for turbomachinery applications. In gaseous hydrocarbon fuels, four formation pathways have been identified: thermal, prompt, $\mathrm{N}_{2} \mathrm{O}$, and $\mathrm{NNH}[10]$. Achieving low- $\mathrm{NO}_{x}$ configurations requires a detailed understanding of pathway interactions, especially in the gas turbine industry, where lean, premixed configurations are developed to steadily reduce emissions below $10 \mathrm{ppm}$. In these conditions, every production route is suspected to significantly contribute to total emissions $[8,11]$. However, the prompt, $\mathrm{N}_{2} \mathrm{O}$, and $\mathrm{NNH}$ channels have received little interest compared to the thermal channel, and they are not as well understood.

The introduction of uncertainty analysis in combustion research provides additional tools to study the relationship between parametric kinetic values, often obtained after optimization, and selected quantities of interest. Quantifying uncertainties in thermochemical models has been acknowledged as a necessary step in every model development $[12,13]$. Sampling methods were traditionally used to quantify the impact of parametric uncertainty on predictions in combustion [14], but the introduction of spectral methods [15], requiring significantly fewer evaluation points, has provided an economic avenue to quantify chemical interactions. For instance, uncertainty propagation and inference were performed for ignition delay times and laminar flame speeds to constrain prior distributions $[13,16]$, and syngas model optimizations have been performed under uncertainties using PrIME in a robust approach to develop mechanisms [17]. The uncertainties in the nitrogen chemistry have been studied through various approaches for multiple configurations $[11,14,18,19]$, but little interest has been seen regarding the quantification of uncertainties in emissions at engine-relevant pressures.

This work focuses on quantifying the uncertainties in NO concentrations at various pressures up to 32 atm to understand how prediction intervals change towards enginerelevant pressures. With scarce high-pressure NO mea- surements to optimize and validate current thermochemical mechanisms, the nitrogen chemistry is generally used outside its validated range during combustor design. By propagating parametric uncertainties of key reactions in the thermochemical mechanism through one-dimensional freelypropagating flames, NO prediction intervals are obtained. Estimating the change in prediction uncertainty from atmospheric to high-pressure conditions would help to identify promising designs for the desired operating conditions. The subsequent use of reaction pathway analysis provides insight into the contribution of each formation pathway to total emissions to identify major sources of uncertainties at pressures. Understanding the interactions between the four production routes, and their respective active parameter spaces, will help to formulate further experiments to revise current models and improve high-pressure predictions.

\section{Methodology}

Non-intrusive spectral methods are used to develop high-accuracy surrogate models instead of conventional sampling approaches [20]. The use of polynomial chaos expansion (PCE), introduced by Wiener [15], produces algebraic systems of equations that capture the relationships between the uncertain parameters and the quantities of interest at reduced computational costs [21]. These formulations also identify the contribution of various parametric sources of uncertainty once they are propagated through simulations. The resulting surrogate models, or high-dimension response surfaces, can then be heavily randomly sampled to quantify the uncertainties in the quantities of interest, perform model optimization, and constrain prior parametric distributions. Non-intrusive techniques have received particular interest in the community as they can be used with legacy code without major modifications.

The current work follows the approach in [19] that uses a combination of Cantera 2.4 [22], to perform one-dimensional flame simulations, and Dakota 6.8 [23] to construct the surrogate model for uncertainty quantification. The uncertainty in the specific reaction rate constants is propagated through the calculations to quantify the uncertainty in predictions of $\mathrm{NO}$ species, or provide "error bars" on solutions. The analysis is performed with a thermochemical model assembled using the base chemistry of the San Diego mechanism 2016 [24], optimized for accurate peak concentration of methylidyne radicals, $[\mathrm{CH}]_{\text {peak }},[25]$ and the nitrogen chemistry from the NOMecha 2.0 mechanism [26]. The resulting "small" detailed mechanism contains 82 species and 505 reactions.

A subset of reactions is first identified to constrain the set of active parameters for the uncertainty quantification, in order to limit the effect of the curse of dimensionality and, therefore, reduce computational effort. A selection of 30 reactions is analysed to provide a set large enough to encompass the most important reactions in the thermochemical model. The surrogate model is then developed using a level $2, \ell_{2}$, nested sparse grid approach to provide $5^{\text {th }}$-order polynomial approximations per dimension and pair-wise interactions reaching $4^{\text {th }}$-order polynomials. 


\section{Identifying uncertain parameters}

The 30 most important reactions are selected using an uncertainty-weighted sensitivity analysis, shown in Appendix A, to quantify the impact of major uncertainty sources with a limited set of reactions [27]. Logarithmic sensitivities (L.S.) are first calculated to identify reactions that greatly affect the production of $\mathrm{NO}$ species. Uncertainty factors obtained from the literature then multiply the sensitivity coefficients. The resulting index, an uncertainty-weighted sensitivity coefficient $\left(I_{\text {uwsc }}\right)$, allows for systematic identification of important reactions that exhibit high sensitivity and uncertainty. In other words, the most important reactions are the ones that largely affect the concentration of NO species within the stated uncertainties in specific reaction rate constants.

The uncertainty in the $i^{\text {th }}$ specific reaction rate constant:

$$
k_{i}=A T^{n} \exp \left(-\frac{E_{\mathrm{a}}}{R_{\mathrm{u}} T}\right),
$$

where $A$ is the pre-exponential coefficient, $n$ is the temperature exponent, and $E_{a}$ is the activation energy, is typically found in the literature as one of two options: a variation on the constant value, $\Delta \log _{10} k_{i},[28-30]$ or an uncertainty factor $f_{i}$ [16]. The uncertainty factor is generally favoured for uncertainty quantification purposes as the nominal rate constants in a given mechanism can be readily multiplied with existing combustion software without modification to the source mechanism file. Consequently, uncertainty factors are obtained with $f_{i}=10^{\Delta \log _{10} k_{i}}$ to perform the analysis with multipliers. Physically realistic intervals, compiled in the literature [28-30], provide preferred specific reaction rate constants along with their uncertainty bounds. Additionally, constrained rates for important reactions in ignition delay time and flame speed determinations are used from [16]. These uncertainty factors are given relative to their preferred specific reaction rate constants, resulting in symmetric probable intervals in log space. However, the rates in a given mechanism, denoted here as nominal rates, are often not equal to the preferred rates in [28-30] as they have been adjusted to specific experimental data. Modified uncertainty factors, which will no longer be symmetric, are therefore required to keep the reaction rates, during the uncertainty analysis, within the preferred interval by applying the multiplier $f$, to a rate constant different from the preferred value found in the literature. Consequently, relative errors are expressed for the lower and upper limits of the uncertain parametric space as follows:

$$
\begin{aligned}
& \left.\frac{\Delta k_{i}}{k_{i}}\right|_{\text {low }}=\frac{k_{i, \mathrm{p}} / f_{i, \mathrm{p}}-k_{i, \mathrm{p}}}{k_{i}}=\frac{1}{f_{i, \text { low }}}-1 \text { and } \\
& \left.\frac{\Delta k_{i}}{k_{i}}\right|_{\text {high }}=\frac{k_{i, \mathrm{p}} \cdot f_{i, \mathrm{p}}-k_{i, \mathrm{p}}}{k_{i}}=f_{i, \text { high }}-1,
\end{aligned}
$$

where the subscript $\mathrm{p}$ denotes the preferred values identified in the literature. The resulting limits therefore retain the nominal specific reaction rate constants of the thermochemical mechanism while covering a similar uncertain region as the preferred values. Uniform prior distributions are chosen for the pressure independent reactions as scarce collected measurements do not provide statistical evidence to justify other choices.

Pressure dependent reactions, however, are expressed using the Lindemann approach [31]:

$$
k_{i}=\left(\frac{k_{\infty_{i}} k_{0_{i}}[\mathrm{M}]}{k_{\infty_{i}}+k_{0_{i}}[\mathrm{M}]}\right) F,
$$

where the low and high-pressure constants follow the Arrhenius form and the broadening factor $F$ typically follows the Troe formulation [32]. Uncertainty factors are applied to $k_{0}$ and $k_{\infty}$, and to the fall-off parameter $F_{c}$, if any. The uncertainty limits in the literature therefore change with pressure and need to be adjusted depending on the regime where the calculations are performed. Uniform distributions are initially applied to the $k_{0}, k_{\infty}$, and $F_{c}$ values before evaluating the uncertain distribution of the specific reaction rate constant with pressure. This analysis is demonstrated in Fig. 1a where the uncertainties in the three terms are propagated through the Lindemann formulation for the pressure dependent reaction $\mathrm{N}_{2} \mathrm{O}(+\mathrm{M}) \rightleftharpoons \mathrm{N}_{2}+\mathrm{O}(+\mathrm{M})$. Two types of resulting distributions are observed for the reactions in the range of pressures of interest: (1) uniform distributions are observed in pressure regimes where only one asymptotic branch is active, such as in Fig. 1b; (2) normal distributions are used to approximate the fall-off region between low and high pressures, as seen in Fig. 1c, consistent with the central limit theorem. For the uncertainty analysis, the prior parametric distribution of pressure dependent reactions is therefore expressed by either a uniform or normal distribution depending on the pressure regime.

Consequently, the orthogonal polynomial bases used in the development of the surrogate model become Legendre and Hermite polynomials corresponding to uniform and normal distributions, respectively [33]. Both bases are normalized over their parametric interval to ensure consistency between variables.

\section{Uncertainty quantification with sparse grids}

Inherent parametric uncertainties in thermochemical models have been studied using stochastic methods $[14,18]$ and, more recently, with spectral methods $[12,16]$ that benefit from an economic approach requiring fewer evaluation points. Still, for complex multi-physics phenomena, such as combustion processes, the curse of dimensionality limits the number of parameters evaluated in any practical applications. Sparse grid formulations were found to be a reasonable alternative, providing high-order polynomials per dimension with relatively few collocation points, by neglecting higher-order interactions between variables. Additionally, they support anisotropic development that can result in adaptive methods [34] to provide greater control on the accuracy of the 


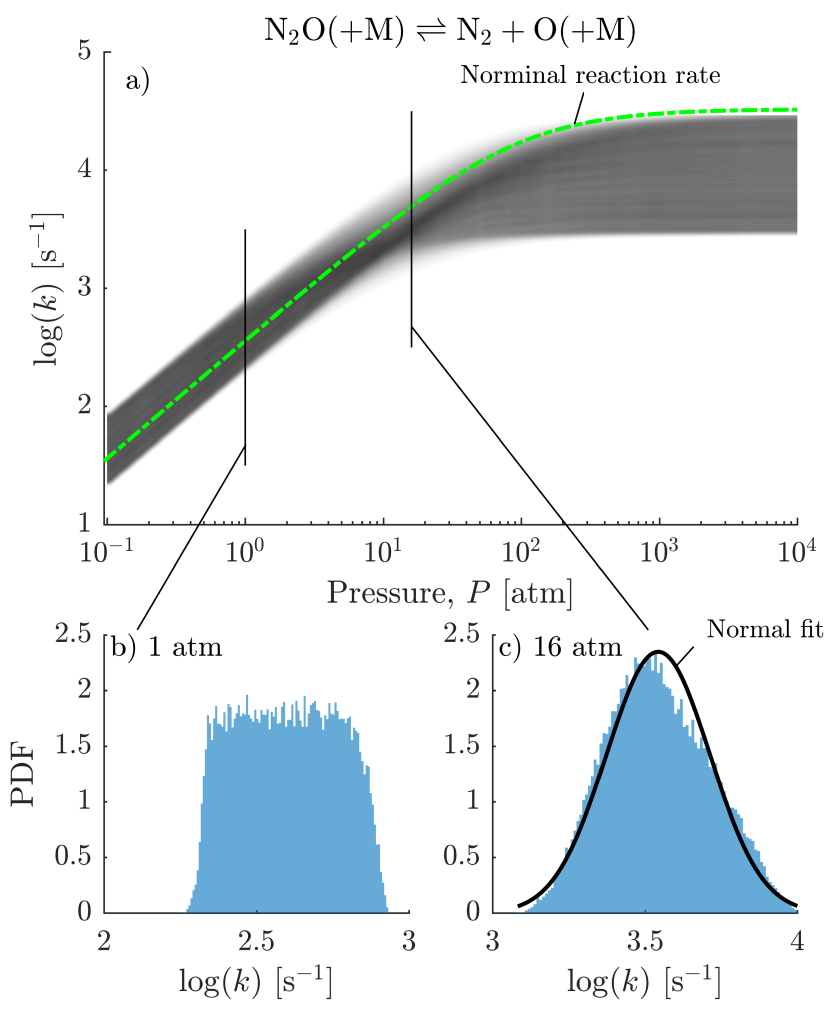

Fig. 1. a) Specific reaction rate constant uncertainty for the pressure dependent $\mathrm{N}_{2} \mathrm{O}(+\mathrm{M}) \rightleftharpoons \mathrm{N}_{2}+\mathrm{O}(+\mathrm{M})$ reaction in an argon atmosphere at $1800 \mathrm{~K}$. The uncertainty on the values $k_{0}, k_{\infty}$, and $F_{c}$ combine in the fall-off region creating non-uniform prior distributions. b) At atmospheric condition, the low pressure regime dominates and the uniform distribution holds. c) At 16 atm, the distribution can be approximated by a Gaussian profile.

approach. In the current work, $\ell_{2}$ sparse grids are used to develop the surrogate models for uncertainty quantification in emissions predictions.

Polynomial chaos expansions, similarly to Fourier series for periodic signals, decompose any response $R$ into an infinite series of polynomials:

$$
\begin{aligned}
R(\mathbf{x})=R_{0} & +\sum_{k_{1}=1}^{\infty} \alpha_{k_{1}} P_{1}\left(x_{k_{1}}\right) \\
& +\sum_{k_{1}=1}^{\infty} \sum_{k_{2}=1}^{\infty} \alpha_{k_{1}, k_{2}} P_{2}\left(x_{k_{1}}, x_{k_{2}}\right) \\
& +\sum_{k_{1}=1}^{\infty} \sum_{k_{2}=1}^{\infty} \sum_{k_{3}=1}^{\infty} \alpha_{k_{1}, k_{2}, k_{3}} P_{3}\left(x_{k_{1}}, x_{k_{2}}, x_{k_{3}}\right)+\ldots
\end{aligned}
$$

where $\mathbf{x}$ contains the uncertain parameters $x, \alpha_{k_{i}}$ are real coefficients of the expansion for the polynomials $P_{j}\left(x_{k_{1}}, \ldots, x_{k_{j}}\right)$ of order $j$. The expansion is written in the compact form:

$$
R(\mathbf{x})=\sum_{k=0}^{\infty} \alpha_{k} \Psi_{k}(\mathbf{x})=\sum_{k=0}^{\infty} \alpha_{k} \prod_{i=1}^{n} \psi_{t_{i}^{k}}\left(x_{i}\right)
$$

for a series of $k$ terms over the $n$ variables studied. A one-to- one correspondence relates the coefficients $\alpha_{k}$ to the polynomials $P_{j}\left(x_{k_{1}}, \ldots, x_{k_{j}}\right)$ and $\Psi_{k}$. The multivariate polynomials $\Psi_{k}(\mathbf{x})$ are expressed using the one-dimensional polynomial bases $\psi_{t_{i}^{k}}$ for the $i^{\text {th }}$ variable, where the polynomial order of the $k^{\text {th }}$ term for the variable $i$ is included in the multi-index $t_{i}^{k}$. For practical purposes, a finite series is obtained by truncating Eq. 6 to the desired polynomial order $p$ :

$$
R(\mathbf{x}) \approx \sum_{k=0}^{K} \alpha_{k} \Psi_{k}(\mathbf{x})
$$

where $K+1$ terms limit the expansion based on the spectral technique employed. In the current analysis, the prior distributions are assigned to the uncertain parameters. Therefore, $\psi_{i}$ and $\Psi_{k}$ are known, leaving only the polynomial coefficients for evaluation. Spectral projections against each orthogonal polynomial basis function are used to obtain $\alpha_{k}$ with:

$$
\alpha_{k}=\frac{\left\langle R, \Psi_{k}\right\rangle}{\left\langle\Psi_{k}, \Psi_{k}\right\rangle}=\frac{1}{\left\langle\Psi_{k}^{2}\right\rangle} \int_{\Gamma} R(\mathbf{x}) \Psi_{k}(\mathbf{x}) \rho_{\mathbf{x}}(\mathbf{x}) d \mathbf{x}
$$

over the multi-dimensional domain $\Gamma$. The quantities of interest $R$ are obtained from complete solutions of the direct simulations of one-dimensional flames and the joint probability density function $\rho_{\mathbf{x}}$ is derived from the prior parametric distributions. For structured grids used in this work, deterministic quadrature methods are used to evaluate the coefficients. The one-dimensional quadrature operator approximates the integral in Eq. 8 over the first dimension $\Gamma_{1}$ with:

$$
I^{(1)} f=\int_{\Gamma_{1}} f(\mathbf{x}) d \mathbf{x} \approx \sum_{r=1}^{m} f\left(\mathbf{x}^{r}\right) w^{r}=Q^{(1)} f
$$

where $f(\mathbf{x})=R(\mathbf{x}) \Psi_{k}(\mathbf{x}) \rho_{\mathbf{x}}(\mathbf{x})$, and the $m$ nodes, $x^{r}$, and $m$ weights, $w^{r}$, are specific to a given quadrature rules. The $n$-dimension quadrature operator is described by:

$$
\begin{aligned}
Q_{\ell}^{(n)} f(\mathbf{x}) & =\left(Q_{\ell_{1}}^{(1)} \otimes \ldots \otimes Q_{\ell_{n}}^{(1)}\right) f(\mathbf{x}) \\
& =\sum_{j_{1}=1}^{m_{\ell_{1}}} \ldots \sum_{j_{n}=1}^{m_{\ell_{n}}} f\left(x_{j_{1}}^{\ell_{1}} \ldots x_{j_{n}}^{\ell_{n}}\right)\left(w_{j_{1}}^{\ell_{1}} \otimes \ldots \otimes w_{j_{n}}^{\ell_{n}}\right),
\end{aligned}
$$

along the $\ell^{\text {th }}$-level of integration. The resulting tensorproduct rule is used to evaluate the multi-dimensional integral in Eq. 8. Nested rules, used in the current work, require the introduction of the quadrature operator $\Delta_{\ell}$. These formulations reuse points from previous levels, $\ell-1$, to express the change between two levels of development. Similarly to Eq. 9 and 10, the one-dimensional quadrature operator $\Delta_{\ell}^{(1)}$ can be obtained by

$$
\Delta_{\ell}^{(1)} f(\mathbf{x})=\left(Q_{\ell}^{(1)}-Q_{\ell-1}^{(1)}\right) f(\mathbf{x}),
$$


before generalizing to the $n$-dimension quadrature operator

$$
Q_{\ell}^{(n)} f(\mathbf{x})=\sum_{\max \ell^{\prime} \leq \ell}\left(\Delta_{\ell_{1}}^{(1)} \otimes \ldots \otimes \Delta_{\ell_{n}}^{(1)}\right) f(\mathbf{x})
$$

where $\ell^{\prime}=\left(\ell_{1}, \ldots, \ell_{n}\right)$ is a multi-index that contains the levels of accuracy $\ell_{i}$ for each variable $i$. The resulting quadrature formulation in Eq. 12 is used to evaluate the coefficients of the PCE in techniques known as tensor-product expansions $[21,35]$.

To provide similar accuracy with fewer quadrature points, sparse grids were introduced for high-dimensional problems [36]. This approach retains only a subset of the tensor-product expansion by changing the summation rule. In this case, multivariate terms are limited to low-order interactions, reducing the increase in collocation points due to the curse of dimensionality. The sparse grid quadrature rule at the $\ell^{\text {th }}$ level only differs from Eq. 12 by the definition of the summation limit, following

$$
Q_{\ell}^{(n)} f(\mathbf{x})=\sum_{\left|\ell^{\prime}\right| \leq \ell+n-2}\left(\Delta_{\ell_{1}}^{(1)} \otimes \ldots \otimes \Delta_{\ell_{n}}^{(1)}\right) f(\mathbf{x})
$$

where the summation over $\left|\ell^{\prime}\right|=\ell_{1}+\ldots+\ell_{n}$ regulates the growth in number of required collocation points as more parameters are studied.

\section{Surrogate modelling for species concentrations}

The current work focuses on quantifying uncertainties in the predictions of NO species. Surrogate models are developed using sparse grids for the concentration of $\mathrm{NO}$, and also $\mathrm{CH}$ to investigate the impact of parametric uncertainties on the prompt-NO precursor. To accurately construct the response surfaces, logarithms of the species concentrations are used as the quantities of interest, $R$, when evaluating the coefficients $\alpha_{k}$ through spectral projection in Eq. 8. It therefore limits the quantities of interest to strictly positive values to prevent extrapolation errors to non-physical, negative concentrations when the surrogate models are sampled over the entire domain. Consequently, the uncertainty analysis is performed for $\log _{10} X_{\mathrm{NO}}$ and the results are transformed back to mole fractions, $X_{\mathrm{NO}}$, to present ppm values.

\section{Results}

The $I_{\text {uwsc }}$ are evaluated using a thermochemical mechanism assembled with the base chemistry of the San Diego mechanism 2016 [24], optimized for accurate peak concentration of methylidyne radicals, $[\mathrm{CH}]_{\text {peak }},[25]$ and the nitrogen chemistry from the NOMecha 2.0 mechanism [26]. The analysis is performed $10 \mathrm{~ms}$ downstream of the flame front, identified as the location of the $\mathrm{CH}$-radical peak concentration, to select reactions that affect NO emissions on a residence time scale comparable to combustion systems found in the gas turbine industry. The analysis is performed across a range of pressures varying from $1 \mathrm{~atm}$ to $32 \mathrm{~atm}$ and the 30 reactions that present the highest index, defined previously, are listed in Appendix A. The analysis performed is limited by our description of the combustion process and focuses solely on the effect of parametric uncertainties. Understanding the effects of structural uncertainties, such as chemically termolecular reactions [37], or non-linear mixing rules [38], would require further analysis and likely result in larger prediction uncertainties.

The uncertainties of the specific reaction rate constants of these reactions are propagated through adiabatic, freelypropagating flame simulations to study nitrogen chemistry without hydrodynamic stretch effects. The simulations are performed for a lean, $\phi=0.7$, mixture of methane and air at $293 \mathrm{~K}$ and at pressures of $1,2,4,8,16$, and 32 atm. The resulting flame temperatures are relatively constant over the range of pressures studied and reach $\sim 1835 \mathrm{~K}$. The NO concentrations are first obtained to quantify the uncertainties in predictions as pressure increases to engine-relevant conditions. Reaction pathways analyses are subsequently performed to identify the contribution of each formation channel to total emissions across the range of pressure. Throughout this analysis, concentration profiles are reported against residence time, $\tau_{\text {res }}$, relative to the flame front, with zero corresponding to the location of $[\mathrm{CH}]_{\text {peak }}$. The residence time is obtained by integrating the distance divided by local velocity over the numerical domain.

\section{$\mathrm{NO}_{x}$ emissions with pressure}

Concentration profiles are first presented for increasing operating pressures in Fig. 2. NO concentrations are then recast against pressure at the residence time of $10 \mathrm{~ms}$, chosen as the target for the uncertainty-weighted sensitivity analysis, in Fig. 3 to visualize the impact of pressure on emissions predictions and uncertainties. The prediction uncertainty is displayed as grey shading, where darker regions correspond to higher probability of obtaining a specific realization in the uncertainty space covered by the 30 reactions identified. Statistics of the distributions are also evaluated to bound the shaded area with the $68 \%$ and $95 \%$ intervals and ease the comparison between simulation results. Additionally, the nominal solutions of the thermochemical mechanism are presented for the range of operating pressures.

At the conditions studied, and for residence times comparable to conventional combustion systems, few differences in nominal profiles are observed as the pressure is increased from 1 to $32 \mathrm{~atm}$, to engine-relevant pressures. The formation of $\mathrm{NO}$ in the flame front increases to pressures of $8 \mathrm{~atm}$ and subsequently reduces at higher pressures. In the postflame region, the rate of production of NO increases with pressure, as can be seen from the increasing post-flame slope in the concentration profiles.

Interestingly, the uncertainty interval decreases as the pressure is increased to engine-relevant conditions. This seems counter-intuitive as we could expect the model to be more uncertain at conditions where accurate validation and optimization targets are scarcer, especially for time-resolved 

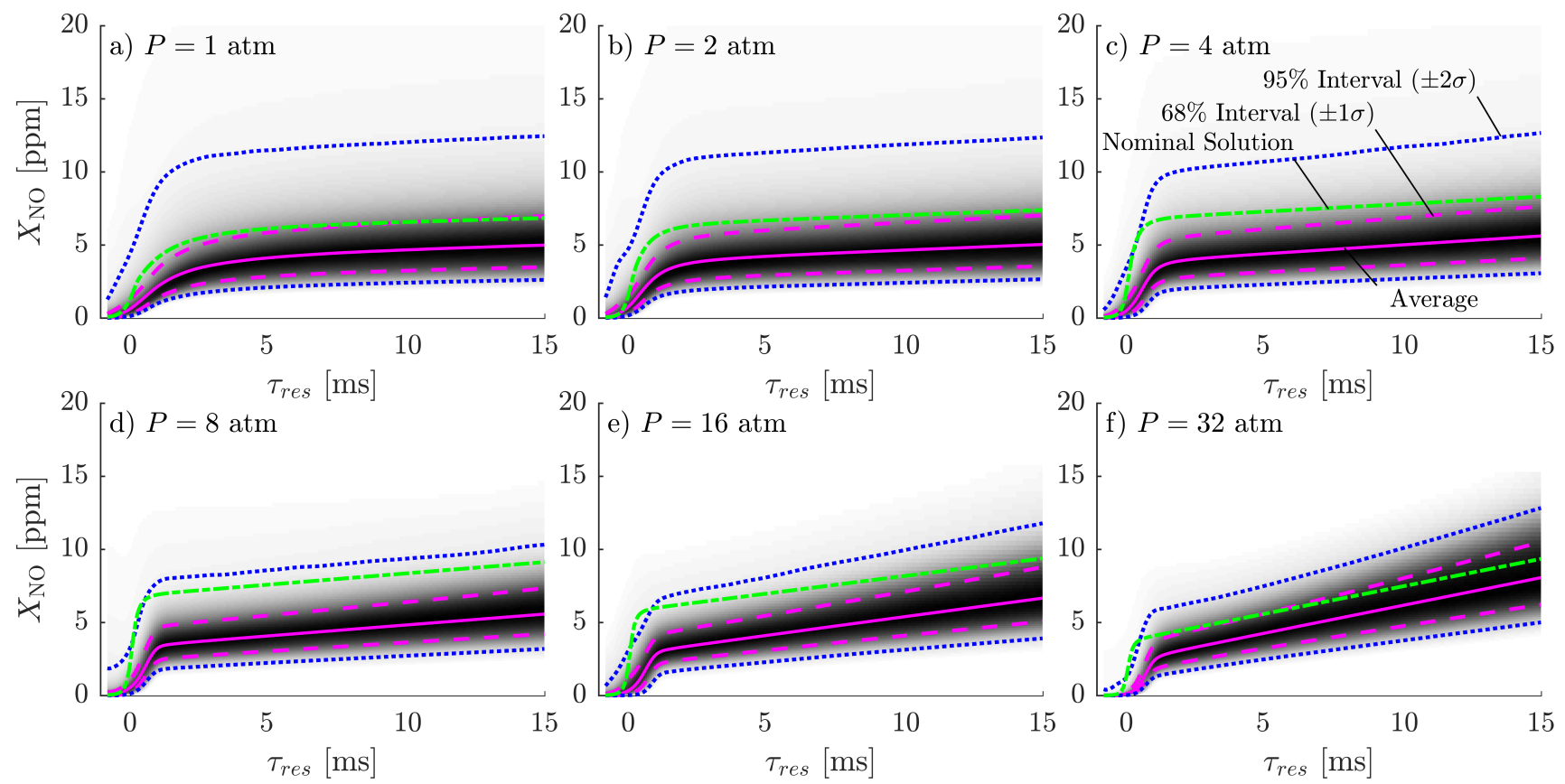

Fig. 2. [NO] profiles for freely-propagating flames in lean, $\phi=0.7$, methane-air mixtures. Operating pressures of: a) 1 atm, b) 2 atm, c) $4 \mathrm{~atm}$, d) $8 \mathrm{~atm}$, e) $16 \mathrm{~atm}$, and f) $32 \mathrm{~atm}$ are shown. The shading expresses the probability of predicting a given quantity of NO emissions with darker regions corresponding to higher probabilities. Nominal solutions are shown as - - Statistics of the distributions are presented for the average by - the $68 \%( \pm 1 \sigma)$ intervals by --- , and the $95 \%( \pm 2 \sigma)$ by $\cdots \cdots$. (The reader is referred to the web version of this article for the colour interpretation of the figure legend.)

species concentrations. Since this analysis focuses on quantifying the impact of specific reaction rate constants, additional uncertainties in the selection of collision efficiencies and the mechanism structure itself could increase the prediction interval. It is worth mentioning that, although the nominal response is within the uncertainty limits, the NO production in the flame zone is found to yield concentrations above the $1 \sigma$ limit for all pressures, and even extends beyond the $2 \sigma$ line for elevated pressures. Furthermore, the $[\mathrm{CH}]_{\text {peak }}$, known as the precursor to prompt-NO formation, does follow a similar trend with pressure as the nominal concentration extends further than the upper $2 \sigma$ limit. With several nomi-

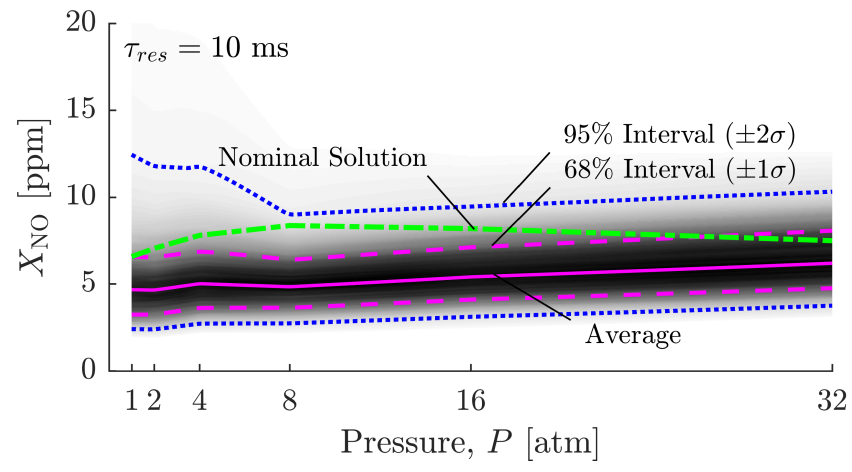

Fig. 3. Evolution of the [NO] uncertainty limits with increased pressure at $\tau_{\text {res }}=10 \mathrm{~ms}$. Nominal solutions are shown as - '- '. Statistics of the distributions are presented for the average by - , the $68 \%( \pm 1 \sigma)$ intervals by --- , and the $95 \%( \pm 2 \sigma)$ by $\cdots \cdots$. nal reactions close to the uncertainty limits of the evaluation, due to the asymmetric definition of the uncertainty factors, the nominal mechanism does not lie in the most probable region for most of the profiles. It is suspected that a different set of reactions, obtained with reactions that greatly affect $\mathrm{NO}$ formation in the flame front, or $\mathrm{CH}$ formation, in addition to those used here, would increase the predicted limits.

The uncertainty reduction is most apparent by comparing the upper $2 \sigma$ uncertainty limit of the 1 and $32 \mathrm{~atm}$ cases. The probability distribution, or the shading, drastically changes towards a shape that is closer to a normal distribution. At low pressures, the concentration profiles exhibit a wider distribution tail extending to higher concentration values, shown by the light-grey regions. This type of uncertainty distribution in NO prediction typically arise from the prompt pathway where the uncertainty distributions in $[\mathrm{CH}]_{\text {peak }}$ propagate through the calculations [19]. The change in shape towards higher pressures tends to indicate that the contribution of the prompt pathway to total emissions and uncertainty is weak, which is subsequently confirmed by reaction pathway analyses. No reduction of the $\pm 1 \sigma$ interval is observed for $\mathrm{NO}$ concentrations at $10 \mathrm{~ms}$ in Fig. 3.

Investigating further into the narrower NO uncertainty distributions at elevated pressures and the reducing contribution of prompt-NO, the probability distribution of $[\mathrm{CH}]_{\text {peak }}$ along with nominal $\mathrm{CH}$ profiles are shown in Fig. $4 \mathrm{a}$ and b, respectively, for the same operating pressures. Nominal profiles indicate that $\mathrm{CH}$ concentrations decrease systematically with pressure. The $[\mathrm{CH}]_{\text {peak }}$ values are halved as the pressure 

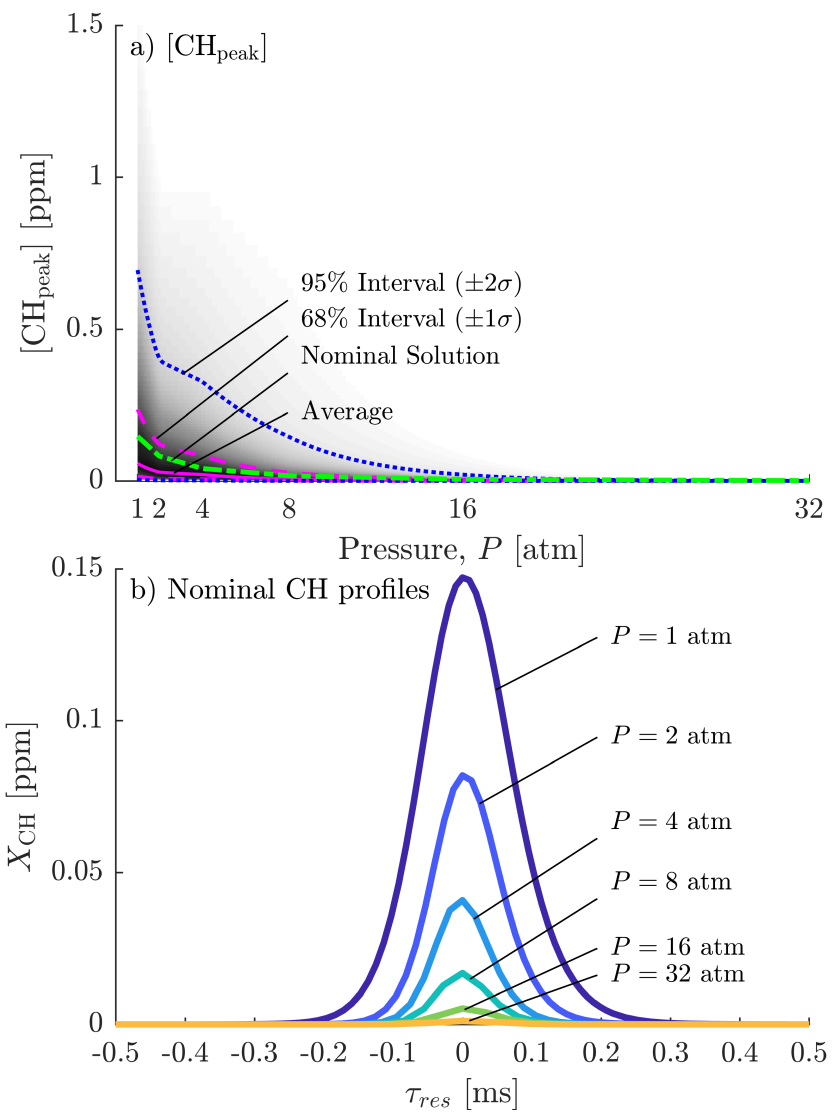

Fig. 4. a) Uncertainty distribution of the $\left[\mathrm{CH}_{\text {peak }}\right]$ with pressure. Nominal solutions are shown as $=\cdots$. Statistics of the distributions are presented for the average by - , the $68 \%( \pm 1 \sigma)$ intervals by - - - , and the $95 \%( \pm 2 \sigma)$ by $\cdots . .$. b) Nominal $\mathrm{CH}$ profiles exhibit a steadily decreasing maximum concentration and thinner $\mathrm{CH}$ layer thickness with pressure.

is doubled, leading to a reduction of more than one order of magnitude in nominal predictions at $32 \mathrm{~atm}$. Additionally, the expected thinner flames at increased pressure lead to a shorter residence time in the $\mathrm{CH}$ layer. Recent measurements of $\mathrm{C}_{1}-\mathrm{C}_{4}$ alkanes and alcohols confirmed that the prompt-NO formation scales linearly with peak $\mathrm{CH}$ concentration when scaled with the residence time in the $\mathrm{CH}$ layer [39]. These two effects, observed in nominal solutions, both result in a reduction of prompt-NO formation and, consequently, the absolute uncertainty in $\mathrm{CH}$ predictions decreases with pressure, as shown in Fig. 4a. The impact of uncertainties in the $\mathrm{CH}$ chemistry, propagating through the prompt pathway, should then be reduced at pressure, consistent with the results shown in Figs. 2 and 3.

\section{Pathways contribution to emissions}

A detailed investigation of the formation pathways in the nitrogen chemistry is conducted using Reaction Pathway Analysis (RPA) following the implementation in [40-42]. This approach provides a visual representation of the complex thermochemical mechanism to help understand the interactions between the species and reactions. By connecting the species of the mechanism, as nodes, with arrows representing reactions, dense mechanism files become relation graphs where chemical pathways can clearly be identified. The approach used here conserves the flux of atomic nitrogen $(\mathrm{N})$, which is a scalar, and tracks it as reactants are being consumed to products before exiting the control volume. The rate of transfer from species $s_{1}$ to $s_{2}, R\left(\mathrm{~N}, s_{1}, s_{2}\right)$. is spatiallyintegrated with:

$$
R\left(\mathrm{~N}, s_{1}, s_{2}\right)=\int_{x_{\mathrm{i}}}^{x_{\mathrm{f}}} \sum_{l} n_{l}\left(\mathrm{~N}, s_{1}, s_{2}\right) \cdot q_{l}(x) \cdot \pi r^{2} \mathrm{~d} x,
$$

where the number of $\mathrm{N}$ atoms, $n_{l}$, is transferred from species $s_{1}$ to $s_{2}$ in reaction $l, q_{l}(x)$ represents the rate of progress of reaction $l, r$ is the radius of the cylindrical control volume, and $x$ is the spatial domain. The cylindrical volume is adjusted over the domain with inlet and outlet boundaries, $x_{\mathrm{i}}$ and $x_{\mathrm{f}}$, to obtain a known inlet flux. The fraction of the flux going through the reaction $l$ is then obtained by evaluating the integral in Eq. 14. In the nitrogen chemistry, it is therefore possible to evaluate the contribution of each of the four formation pathways to total emissions through well-defined initiation reactions. Only a single evaluation is required to identify the contribution of each channel, contrary to methods where initiation reactions are turned on and off [43]. Additionally, RPAs study the entire mechanism at once, reducing the risks of potentially introducing structural errors when removing initiation reactions from channels that interact back with the core chemistry.

The analysis is performed in freely-propagating flames using a lean, $\phi=0.7$, methane-air mixture at pressures varying from 1 to $32 \mathrm{~atm}$. The control volume outlet location is adjusted to yield residence times of $10 \mathrm{~ms}$ to allow for systematic comparison between pressures. The limit cases are shown in Fig. 5a and b for pressures of 1 and $32 \mathrm{~atm}$, respectively. The rates of transfer are presented by arrows where the width is scaled using the fraction of the flux going from species $s_{1}$ to $s_{2}$. To ease visualization and identify major pathway interactions, a selection of minor species are lumped under $\mathrm{H}_{\alpha} \mathrm{N}_{\beta} \mathrm{C}_{\gamma} \mathrm{O}_{\delta}$ and only rates of transfer larger than $1 \%$ are shown in Fig. 5a and b. The contribution of each NO production route to total NO concentration is then evaluated by tracking the flux of atomic nitrogen through the initiation reactions, with key species shown on the second row, and exiting the control volume as NO molecules. The relative contribution is presented in Fig. 5c for the range of pressures studied along with the nominal NO profile.

At atmospheric pressure, every pathway is contributing significantly to total $\mathrm{NO}$ emissions. The four routes are clearly identified in Fig. 5a and the $\mathrm{N}_{2} \mathrm{O}$, thermal, and prompt pathways exhibit similar contributions with $35 \%, 26 \%$, and $26 \%$, respectively. As pressure increases, the relative contribution of the prompt and NNH pathways decrease monotonically, the $\mathrm{N}_{2} \mathrm{O}$ contribution increases, as expected from the pressure-dependent reaction, and the thermal contribution decreases slightly until 5 atm before increasing again towards higher pressures. At $32 \mathrm{~atm}$ (Fig. 5b), the contribu- 

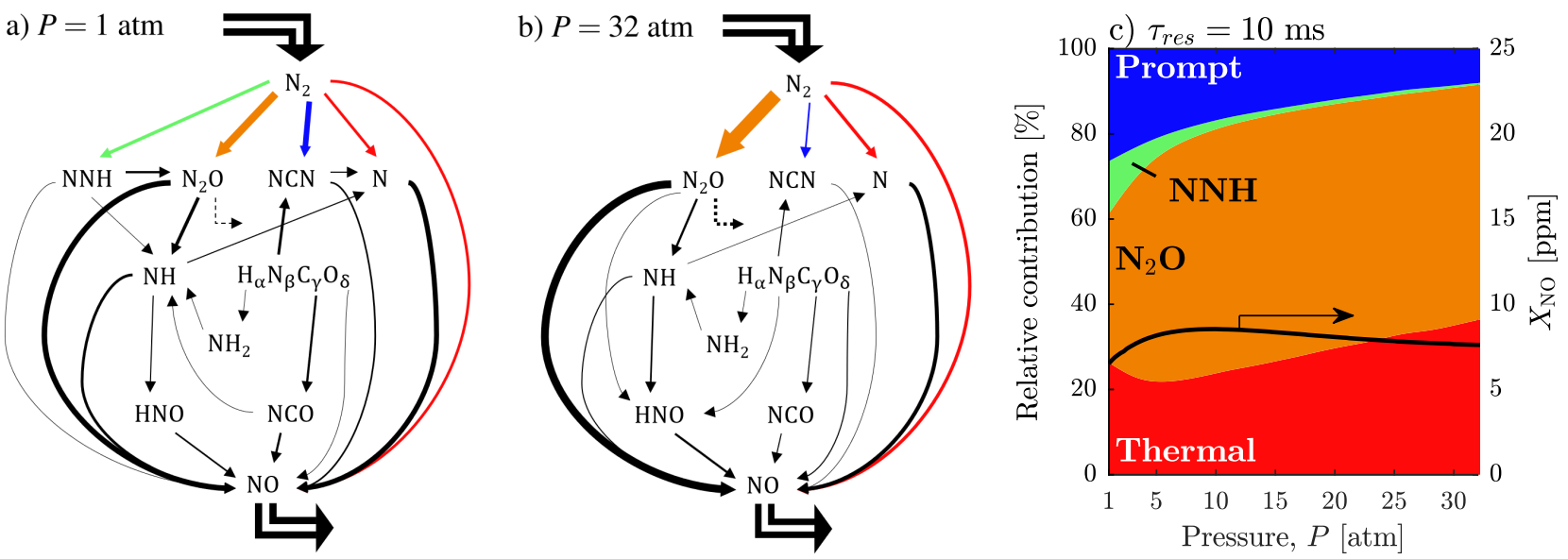

Fig. 5. Reaction Pathway Analysis (RPA) performed for lean, $\phi=0.7$, methane-air mixtures at $\tau_{\text {res }}=10$ ms in a) atmospheric conditions and $\mathrm{b}$ ) at $32 \mathrm{~atm}$. The width of the arrows corresponds to the magnitude of the flux of atomic nitrogen consumed from one species to the other. Only fluxes greater than $1 \%$ are shown to ease reading. Coloured arrows identify the initiation reactions of the four NO formation routes. c) Contribution of each NO production pathway to total emissions. Nominal NO emissions are shown by the solid curve.

tion of the NNH route is considered negligible, effectively removing the production pathway from the RPA graph, and the $\mathrm{N}_{2} \mathrm{O}$ contribution dominates total $\mathrm{NO}$ formation. The decreasing prompt-NO contribution with pressure further supports the findings that predictions are less uncertain at elevated pressures because of the smaller impact of inherent parametric uncertainty in reactions involved in the $\mathrm{CH}$ pathway. As the contribution of the prompt pathway to total emissions diminishes, its contribution to uncertainty is also reduced. This behaviour is consistent with Fig. 2 where the wide distribution tail, characteristic of the propagated $\mathrm{CH}$ uncertainty through the prompt pathway, decreases rapidly with pressure.

Once the pressure reaches $10 \mathrm{~atm}$, the contribution of the $\mathrm{N}_{2} \mathrm{O}$ route remains fairly constant and the increase in thermal contribution simply results from the decreasing prompt contribution, for the studied pressures. This seems to indicate that beyond the rapid change in relative contribution at lower pressures, the pressure-dependent $\mathrm{N}_{2} \mathrm{O}$ reaction does not favour more $\mathrm{NO}$ formation at engine-relevant pressures. In fact, the absolute contribution, in ppm, of this pathway decreases slightly in opposition to the thermal pathway. The pressure-dependent relative $\mathrm{N}_{2} \mathrm{O}$ contribution at lower pressures, and its interaction with the thermal route at higher pressures, would suggest that experiments in the range of pressures of 1-20 atm are ideal for model validation and optimization of the reactions involved in these pathways at engine-relevant conditions.

\section{Conclusion}

The development of future low-emission combustion systems requires accurate design tools to explore the feasible design space numerically and minimize the risks and costs associated with new technology development. Additionally, these tools should be robust to operating conditions and provide at least an estimate of the error on predictions. Thermochemical mechanisms are at the core of these software and are used on a daily basis. Still they are inherently uncertain. Understanding the sources of uncertainties and their impact on predictions should be paramount for any applications.

The current paper investigates the impact of kinetic uncertainties at elevated pressures relevant to the gas turbine industry. An uncertainty-weighted sensitivity analysis performed in lean, $\phi=0.7$, methane-air mixtures identified 30 reactions that greatly affected NO formation $10 \mathrm{~ms}$ downstream from the flame front. The uncertainties in the specific reaction rate constants of these reactions were propagated through one-dimensional freely-propagating flames to obtain prediction intervals for $\mathrm{NO}$ concentrations across a range of pressures up to $32 \mathrm{~atm}$. The analysis showed that, although key reactions in the subset studied become increasingly sensitive with pressure, the uncertainty in NO predictions decreases with pressure. The narrowing of the prediction interval is found to be mainly caused by the diminishing contribution of prompt-NO formation to uncertainty, through the $\mathrm{CH}$ chemistry. The narrower high-pressure distribution observed in lean conditions would suggest that thermochemical mechanism validation for $\mathrm{NO}$ concentration performed at elevated pressures could better distinguish model inaccuracies outside the prediction intervals. Additionally, reaction pathway analysis suggests that experimental NO concentration measurements between 1-20 atm are required to accurately capture the fall-off transition between the low- and high-pressure regimes.

For design purposes, the narrow high-pressure distributions with the $\pm 1 \sigma$ interval predicting approximately 5 $8 \mathrm{ppm}$ at $10 \mathrm{~ms}$ suggest that well calibrated thermochemical models in the studied conditions should capture the proper magnitude of emissions, but might not be able to identify the best configuration with confidence. More importantly, the analysis conducted for uncertain reaction rates demonstrates that, for NO concentrations, the prediction uncertainty does not increase with pressure, and, in fact, decreases due to the reduced influence of the prompt-NO route at pressures. 


\section{Permission for use}

The content of this paper is copyrighted by Siemens Canada Ltd. and is licensed to ASME for publication and distribution only. Any inquiries regarding permission to use the content of this paper, in whole or in part, for any purpose must be addressed to Siemens Canada Ltd. directly.

\section{Acknowledgements}

The authors wish to acknowledge the support of the Natural Sciences and Engineering Research Council of Canada (NSERC), the Fonds de Recherche du Québec - Nature et Technologies and Siemens Canada Limited.

\section{References}

[1] Bergthorson, J. M., and Thomson, M. J., 2015. “A review of the combustion and emissions properties of advanced transportation biofuels and their impact on existing and future engines". Renew. Sust. Energ. Rev., 42, pp. 1393-1417.

[2] Lieuwen, T., Chang, M., and Amato, A., 2013. "Stationary gas turbine combustion: Technology needs and policy considerations". Combust. Flame, 8(160), pp. 1311-1314.

[3] Schofield, K., 2012. "Large scale chemical kinetic models of fossil fuel combustion: Adequate as engineering models - No more, no less". Energ. Fuel., 26(9), pp. 5468-5480.

[4] Smith, G. P., Golden, D. M., Frenklach, M., Moriarty, N. W., Eiteneer, B., Goldenberg, M., Bowman, C. T., Hanson, R. K., Song, S., Gardiner, W. C. J., Lissianski, V. V., and Qin, Z., 1999. GRI-Mech 3.0. http://www. me.berkeley.edu/gri_mech/.

[5] Zhou, C.-W., Li, Y., O'Connor, E., Somers, K. P., Thion, S., Keesee, C., Mathieu, O., Petersen, E. L., DeVerter, T. A., Oehlschlaeger, M. A., et al., 2016. "A comprehensive experimental and modeling study of isobutene oxidation". Combust. Flame, 167, pp. 353379.

[6] Versailles, P., Durocher, A., Bourque, G., and Bergthorson, J. M., 2019. "Measurements of the reactivity of premixed, stagnation, methane-air flames at gas turbine relevant pressures". J. Eng. Gas Turb. Power, 141(1).

[7] Burke, M. P., Dryer, F. L., and Ju, Y., 2011. “Assessment of kinetic modeling for lean $\mathrm{H}_{2} / \mathrm{CH}_{4} / \mathrm{O}_{2} /$ diluent flames at high pressures". Proc. Combust. Inst., 33(1), pp. 905-912.

[8] Versailles, P., Durocher, A., Bourque, G., and Bergthorson, J. M., 2019. "Nitric oxide formation in lean, methane-air stagnation flames at supra-atmospheric pressures". Proc. Combust. Inst., 37(1), pp. 711-718.

[9] Glarborg, P., Miller, J. A., Ruscic, B., and Klippenstein, S. J., 2018. "Modeling nitrogen chemistry in combustion”. Prog. Energ. Combust., 67, pp. 31-68.

[10] Miller, J. A., and Bowman, C. T., 1989. "Mechanism and modeling of nitrogen chemistry in combustion". Prog. Energ. Combust., 15(4), pp. 287-338.

[11] Lipardi, A. C., Versailles, P., Watson, G. M., Bourque, G., and Bergthorson, J. M., 2017. "Experimental and numerical study on $\mathrm{NO}_{x}$ formation in $\mathrm{CH}_{4}$-air mixtures diluted with exhaust gas components". Combust. Flame, 179, pp. 325-337.

[12] Wang, H., and Sheen, D. A., 2015. "Combustion kinetic model uncertainty quantification, propagation and minimization". Prog. Energ. Combust., 47, pp. 1-31.

[13] Prager, J., Najm, H. N., Sargsyan, K., Safta, C., and Pitz, W. J., 2013. "Uncertainty quantification of reaction mechanisms accounting for correlations introduced by rate rules and fitted Arrhenius parameters". Combust. Flame, 160(9), pp. 1583-1593.

[14] Zsély, I. G., Zádor, J., and Turányi, T., 2008. "Uncertainty analysis of NO production during methane combustion”. Int. J. Chem. Kinet., 40(11), pp. 754-768.

[15] Wiener, N., 1938. "The homogeneous chaos". Am. J. Math, 60(4), pp. 897-936.

[16] Sheen, D. A., and Wang, H., 2011. "The method of uncertainty quantification and minimization using polynomial chaos expansions". Combust. Flame, 158(12), pp. 2358-2374.

[17] Slavinskaya, N. A., Abbasi, M., Starcke, J. H., Whitside, R., Mirzayeva, A., Riedel, U., Li, W., Oreluk, J., Hegde, A., Packard, A., Frenklach, M., Gerasimov, G., and Shatalov, O., 2017. "Development of an uncertainty quantification predictive chemical reaction model for syngas combustion”. Energ. Fuel., 31(3), pp. 2274-2297.

[18] Tomlin, A. S., 2006. "The use of global uncertainty methods for the evaluation of combustion mechanisms". Reliab. Eng. Syst. Safe., 91(10-11), pp. 12191231.

[19] Durocher, A., Versailles, P., Bourque, G., and Bergthorson, J. M., 2019. "Impact of Kinetic Uncertainties on Accurate Prediction of NO Concentrations in Premixed Alkane-Air Flames". Combust. Sci. Technol., pp. 1-27.

[20] Frenklach, M., Wang, H., and Rabinowitz, M. J., 1992. "Optimization and analysis of large chemical kinetic mechanisms using the solution mapping method-combustion of methane". Prog. Energ. Combust., 18(1), pp. 47-73.

[21] Smith, R., 2013. Uncertainty Quantification: Theory, Implementation, and Applications. Computational Science and Engineering. SIAM, Philadelphia.

[22] Goodwin, D., Moffat, H., and Speth, R., 2016. Cantera: An object-oriented software toolkit for chemical kinetics, thermodynamics, and transport processes. http://www.cantera.org.

[23] Adams, B., Bauman, L., Bohnhoff, W., Dalbey, K., Ebeida, M., Eddy, J., Eldred, M., Hough, P., Hu, K., Jakeman, J., Stephens, J., Swiler, L., Vigil, D., and Wildey, T., 2015. Dakota, a multilevel parallel objectoriented framework for design optimization, parameter estimation, uncertainty quantification, and sensitivity analysis: Version 6.0 user's manual. Tech. rep., San- 
dia Technical Report SAND2014-4633.

[24] University of California at San Diego, 2016. Chemicalkinetic mechanisms for combustion applications. http: //combustion.ucsd.edu. San Diego Mechanism web page, Mechanical and Aerospace Engineering (Combustion Research).

[25] Versailles, P., Watson, G. M., Durocher, A., Bourque, G., and Bergthorson, J. M., 2018. "Thermochemical mechanism optimization for accurate predictions of $\mathrm{CH}$ concentrations in premixed flames of $\mathrm{C}_{1}-\mathrm{C}_{3}$ alkane fuels". J. Eng. Gas Turb. Power, 140(6).

[26] Lamoureux, N., El Merhubi, H., Pillier, L., de Persis, S., and Desgroux, P., 2016. "Modeling of NO formation in low pressure premixed flames". Combust. Flame, 163, pp. 557-575.

[27] Zádor, J., Zsély, I. G., Turányi, T., Ratto, M., Tarantola, S., and Saltelli, A., 2005. "Local and global uncertainty analyses of a methane flame model". J. Phys. Chem. A, 109(43), pp. 9795-9807.

[28] Baulch, D., Cobos, C., Cox, R., Esser, C., Frank, P., Just, T., Kerr, J., Pilling, M., Troe, J., Walker, R., et al., 1992. "Evaluated kinetic data for combustion modelling". J. Phys. Chem. Ref. Data., 21(3), pp. 411-734.

[29] Baulch, D. L., 2005. "Evaluated kinetic data for combustion modeling : Supplement II". J. Phys. Chem. Ref. Data., 34(3), pp. 757-1397.

[30] Tsang, W., and Hampson, R., 1986. "Chemical kinetic data base for combustion chemistry. Part I. Methane and related compounds". J. Phys. Chem. Ref. Data., 15(3), pp. 1087-1279.

[31] Lindemann, F., Arrhenius, S., Langmuir, I., Dhar, N., Perrin, J., and Lewis, W. M., 1922. "Discussion on "the radiation theory of chemical action"”. T. Faraday Soc., 17, pp. 598-606.

[32] Gilbert, R., Luther, K., and Troe, J., 1983. "Theory of thermal unimolecular reactions in the fall-off range. II. Weak collision rate constants". Ber. Bunsenge. Ph. Chem., 87(2), pp. 169-177.

[33] Askey, R., and Wilson, J. A., 1985. Some basic hypergeometric orthogonal polynomials that generalize Jacobi polynomials, Vol. 319. American Mathematical Society, Providence.

[34] Winokur, J., Kim, D., Bisetti, F., Le Maître, O. P., and Knio, O. M., 2016. "Sparse pseudo spectral projection methods with directional adaptation for uncertainty quantification". J. Sci. Comput., 68(2), pp. 596-623.

[35] Xiu, D., 2010. Numerical methods for stochastic computations: A spectral method approach. Princeton university press, Princeton.

[36] Smolyak, S., 1963. "Quadrature and interpolation formulas for tensor products of certain classes of functions". Soviet Math. Dokl., 4, pp. 240-243.

[37] Burke, M. P., and Klippenstein, S. J., 2017. "Ephemeral collision complexes mediate chemically termolecular transformations that affect system chemistry". Nat. Chem., 9(11), p. 1078.

[38] Burke, M. P., and Song, R., 2017. "Evaluating mixture rules for multi-component pressure dependence: $\mathrm{H}+$
$\mathrm{O}_{2}(+\mathrm{M})=\mathrm{HO}_{2}(+\mathrm{M})$ ". Proc. Combust. Inst., 36(1), pp. 245-253.

[39] Watson, G. M. G., Versailles, P., and Bergthorson, J. M., 2017. "NO formation in rich premixed flames of $\mathrm{C}_{1}-\mathrm{C}_{4}$ alkanes and alcohols". Proc. Combust. Inst., 36(1), pp. 627-635.

[40] Versailles, P., Watson, G. M., Lipardi, A. C., and Bergthorson, J. M., 2016. "Quantitative CH measurements in atmospheric-pressure, premixed flames of $\mathrm{C}_{1}$ $\mathrm{C}_{4}$ alkanes". Combust. Flame, 165, pp. 109-124.

[41] Versailles, P., 2017. " $\mathrm{CH}$ formation in premixed flames of $\mathrm{C}_{1}-\mathrm{C}_{4}$ alkanes: assessment of current chemical modelling capability against experiments". PhD thesis, McGill University.

[42] Grcar, J. F., Day, M. S., and Bell, J. B., 2006. "A taxonomy of integral reaction path analysis". Combust. Theory Model., 10(4), pp. 559-579.

[43] Guo, H., Smallwood, G. J., Liu, F., Ju, Y., and Gülder, Ö. L., 2005. "The effect of hydrogen addition on flammability limit and $\mathrm{NO}_{x}$ emission in ultra-lean counterflow $\mathrm{CH}_{4} /$ air premixed flames". Proc. Combust. Inst., 30(1), pp. 303-311.

[44] Watson, G. M. G., Versailles, P., and Bergthorson, J. M., 2016. "NO formation in premixed flames of $\mathrm{C}_{1}-\mathrm{C}_{3}$ alkanes and alcohols". Combust. Flame, 169, pp. 242-260.

[45] Abian, M., Alzueta, M. U., and Glarborg, P., 2015. "Formation of $\mathrm{NO}$ from $\mathrm{N}_{2} / \mathrm{O}_{2}$ mixtures in a flow reactor: toward an accurate prediction of thermal NO". Int. J. Chem. Kinet., 47(8), pp. 518-532.

\section{Appendix A: Uncertainty-weighted sensitivity analysis}

The 30 reactions used in the uncertainty propagation are identified using uncertainty-weighted sensitivity analyses at pressures of $1,2,4,8,16$, and $32 \mathrm{~atm}$ for a lean, $\phi=0.7$, methane-air mixture. The analysis is performed with the thermochemical mechanism assembled from the nitrogen chemistry NOMecha 2.0 [26], attached to the base chemistry of the San Diego mechanism [24], optimized for accurate peak concentration of methylidyne radicals, $[\mathrm{CH}]_{\text {peak }},[25]$. The uncertainty factors used in the current analysis are extracted from [16,28-30].

The sensitivities of NO concentration, with respect to a $1 \%$ change in the specific reaction rate constants, are obtained for concentrations $10 \mathrm{~ms}$ downstream of the flame front using an adjoint method. Results of the uncertaintyweighted sensitivity analysis are shown in Fig. 6 for the 50 reactions that most affect the concentration of NO species. The reactions are ranked based on their logarithmic sensitivity (L.S.), shown by orange bars, across the range of pressures with the most impactful reactions at the top. The L.S. are then multiplied by $f-1$, shown as yellow bars, to obtain a measure of their effect on emissions predictions within the uncertainty range, and identify reactions that are both impactful and uncertain. For instance, if a reaction is sensitive, but has been studied in greater detail. It generally 


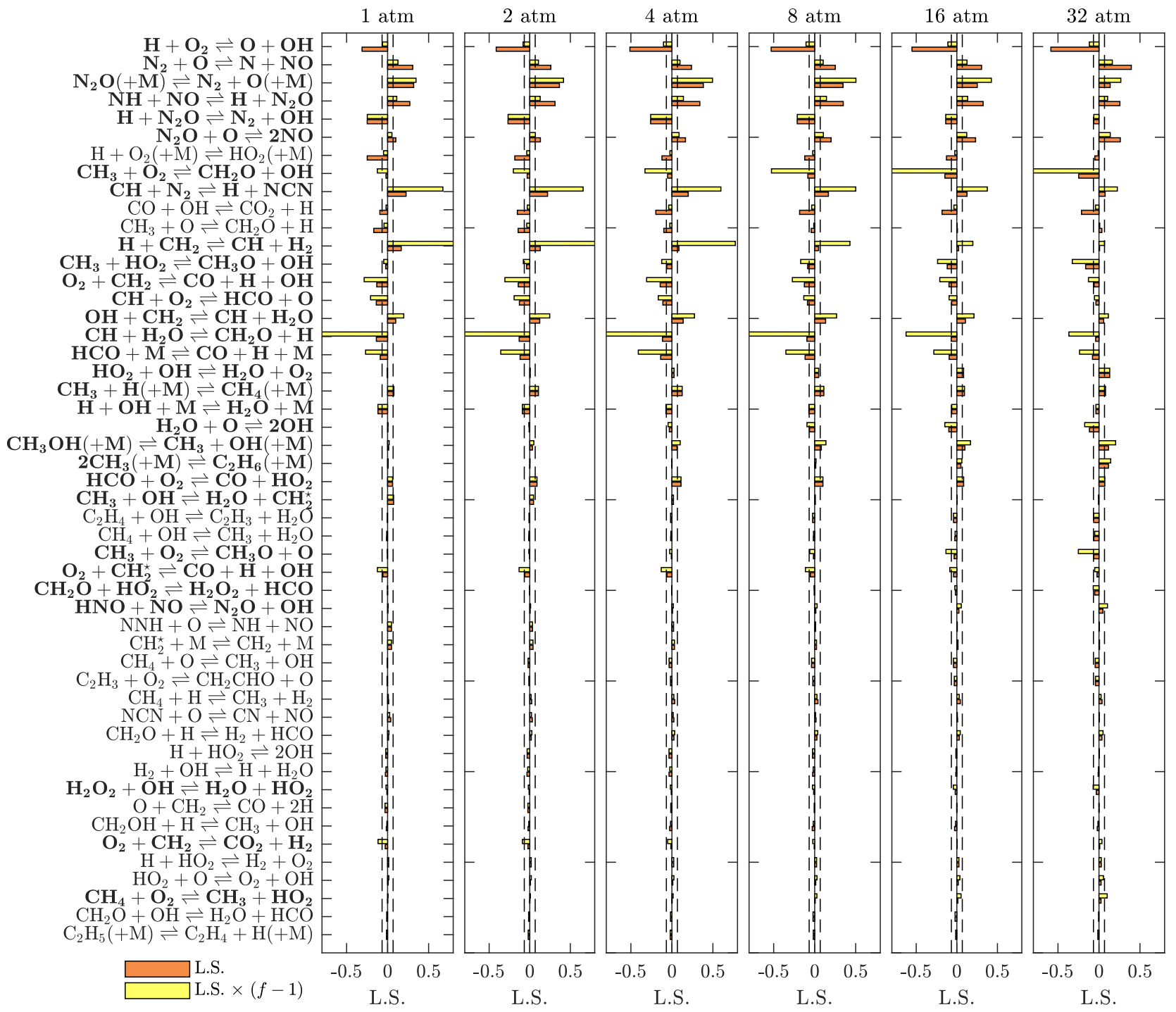

Fig. 6. Uncertainty-weighted sensitivity analysis performed for lean, $\phi=0.7$, methane-air mixtures at increasing pressures. The analysis assesses the sensitivity of NO concentration 10 ms downstream the flame front with respect to changes in specific reaction rate constants. Reactions are ranked based on their logarithmic sensitivity and only the top 50 are displayed.

has a lower uncertainty factor, which might not contribute significantly to total prediction uncertainties, and can be removed from the forward analysis. An example of this is the $\mathrm{H}+\mathrm{O}_{2}(+\mathrm{M}) \leftrightharpoons \mathrm{HO}_{2}(+\mathrm{M})$ reaction. Alternatively, reactions with smaller L.S. index and higher $f-1$ values, such as reactions in the $\mathrm{CH}$ chemistry, can have larger uncertaintyweighted sensitivity indices. This approach provides a robust identification of important reactions for uncertainty quantification as both sensitivity and uncertainty are included in one index to select a subset of reactions for the analysis. The 30 reactions used in the current work are identified by bold font in Fig. 6.

The uncertainty factors for the lower and upper limits, $f_{i, \text { low }}$ and $f_{i \text {, high }}$ respectively, are then evaluated for the subset of identified reactions following the approach in $[19,25]$. The temperature range where a given reaction is active is first identified using net reaction rates. The nominal uncertainty factors are then adjusted to match preferred uncertainty lim- its over the active temperature range. Table 1 presents the important reactions of the assembled thermochemical mechanism with their nominal parameters, where the reaction rate parameters $A, n$, and $E_{\mathrm{a}}$ have units of (cm, mole, $\left.\mathrm{s}\right),(-)$, and (cal, mole), respectively. It also lists the uncertainty limits modified to maintain similar prior uncertainty intervals. For the current analysis, $1 / f_{i \text {, low }}$ of the thermal initiation reaction, $\mathrm{N}_{2}+\mathrm{O} \leftrightharpoons \mathrm{N}+\mathrm{NO}$, has also been lowered to values consistent with recent rate measurements performed in stagnation flames [44] and flow reactors [45]. 
Table 1. Nominal reaction rate parameters and uncertainty bounds $1 / f_{i, \text { low }}$ and $f_{i \text {, high }}$ for the NOMecha 2.0 nitrogen chemistry attached to the base chemistry of the San Diego mechanism.

\begin{tabular}{|c|c|c|c|c|c|c|c|}
\hline & \multicolumn{2}{|l|}{ Reactions } & $\begin{array}{c}A \\
{[\mathrm{~cm}, \mathrm{~mol}, \mathrm{~s}]}\end{array}$ & $n$ & $\begin{array}{c}E_{\mathrm{a}} \\
{[\mathrm{cal}, \mathrm{mol}]}\end{array}$ & $1 / f_{i, \text { low }}$ & $f_{i, \text { high }}$ \\
\hline 1 & $\mathrm{H}+\mathrm{O}_{2} \rightleftharpoons \mathrm{O}+\mathrm{OH}$ & & $3.52 \mathrm{E} 16$ & -0.700 & $17,069.79$ & 0.7979 & 1.174 \\
\hline 2 & $\mathrm{~N}_{2}+\mathrm{O} \rightleftharpoons \mathrm{N}+\mathrm{NO}$ & & $1.00 \mathrm{E} 14$ & 0.000 & 75,490 & 0.4978 & 2.027 \\
\hline \multirow[t]{2}{*}{3} & $\mathrm{~N}_{2} \mathrm{O}(+\mathrm{M}) \rightleftharpoons \mathrm{N}_{2}+\mathrm{O}(+\mathrm{M})$ & $k_{\infty}$ & $1.30 \mathrm{E} 12$ & 0.000 & 62,570 & 0.5000 & 2.000 \\
\hline & & $k_{0}$ & $4.00 \mathrm{E} 14$ & 0.000 & $56,600.0$ & 0.3163 & 3.162 \\
\hline 4 & $\mathrm{NH}+\mathrm{NO} \rightleftharpoons \mathrm{H}+\mathrm{N}_{2} \mathrm{O}$ & & $1.75 \mathrm{E} 14$ & -0.400 & -244 & 0.4495 & 1.000 \\
\hline 5 & $\mathrm{H}+\mathrm{N}_{2} \mathrm{O} \rightleftharpoons \mathrm{N}_{2}+\mathrm{OH}$ & & $3.30 \mathrm{E} 10$ & 0.000 & 4729 & 0.8533 & 3.420 \\
\hline 6 & $\mathrm{~N}_{2} \mathrm{O}+\mathrm{O} \rightleftharpoons 2 \mathrm{NO}$ & & $9.20 \mathrm{E} 13$ & 0.000 & 27,679 & 0.6415 & 1.500 \\
\hline \multirow[t]{3}{*}{7} & $\mathrm{H}+\mathrm{O}_{2}(+\mathrm{M}) \rightleftharpoons \mathrm{HO}_{2}(+\mathrm{M})$ & $k_{\infty}$ & 4.65E12 & 0.440 & 0.00 & 0.7943 & 1.259 \\
\hline & & $k_{0}$ & $5.75 \mathrm{E} 19$ & -1.400 & 0.00 & 0.3163 & 3.162 \\
\hline & & Troe & \multicolumn{3}{|c|}{$A=0.5, T_{3}=1 \mathrm{E}-30, T_{1}=1 \mathrm{E} 30$} & 0.7943 & 1.259 \\
\hline 8 & $\mathrm{CH}_{3}+\mathrm{O}_{2} \rightleftharpoons \mathrm{CH}_{2} \mathrm{O}+\mathrm{OH}$ & & $3.30 \mathrm{E} 11$ & 0.000 & 8941.2 & 0.0229 & 2.774 \\
\hline 9 & $\mathrm{CH}+\mathrm{N}_{2} \rightleftharpoons \mathrm{H}+\mathrm{NCN}$ & & $1.95 \mathrm{E} 12$ & 0.000 & 16,915 & 0.0813 & 1.676 \\
\hline 10 & $\mathrm{H}+\mathrm{CH}_{2} \rightleftharpoons \mathrm{CH}+\mathrm{H}_{2}$ & & $1.93 \mathrm{E} 13$ & 0.000 & -1787.76 & 0.3281 & 36.71 \\
\hline 11 & $\mathrm{CH}_{3}+\mathrm{HO}_{2} \rightleftharpoons \mathrm{CH}_{3} \mathrm{O}+\mathrm{OH}$ & & $5.00 \mathrm{E} 12$ & 0.000 & 0.00 & 1.0000 & 10.84 \\
\hline 12 & $\mathrm{O}_{2}+\mathrm{CH}_{2} \rightleftharpoons \mathrm{CO}+\mathrm{H}+\mathrm{OH}$ & & $5.58 \mathrm{E} 12$ & 0.000 & 1491.4 & 1.0000 & 14.00 \\
\hline 13 & $\mathrm{CH}+\mathrm{O}_{2} \rightleftharpoons \mathrm{HCO}+\mathrm{O}$ & & $8.40 \mathrm{E} 10$ & 0.760 & -478.01 & 1.0000 & 8.762 \\
\hline 14 & $\mathrm{OH}+\mathrm{CH}_{2} \rightleftharpoons \mathrm{CH}+\mathrm{H}_{2} \mathrm{O}$ & & 9.63E06 & 2.000 & 2999.52 & 0.1409 & 1.478 \\
\hline 15 & $\mathrm{CH}+\mathrm{H}_{2} \mathrm{O} \rightleftharpoons \mathrm{CH}_{2} \mathrm{O}+\mathrm{H}$ & & 4.15E15 & -0.800 & 0.00 & 0.0075 & 1.000 \\
\hline 16 & $\mathrm{HCO}+\mathrm{M} \rightleftharpoons \mathrm{CO}+\mathrm{H}+\mathrm{M}$ & & $1.86 \mathrm{E} 17$ & -1.000 & $17,000.48$ & 0.1251 & 2.232 \\
\hline 17 & $\mathrm{HO}_{2}+\mathrm{OH} \rightleftharpoons \mathrm{H}_{2} \mathrm{O}+\mathrm{O}_{2}$ & & $7.00 \mathrm{E} 12$ & 0.000 & -1094.65 & 0.2856 & 3.520 \\
\hline \multirow[t]{3}{*}{18} & $\mathrm{CH}_{3}+\mathrm{H}(+\mathrm{M}) \rightleftharpoons \mathrm{CH}_{4}(+\mathrm{M})$ & $k_{\infty}$ & $9.965 \mathrm{E} 15$ & -0.630 & 382.89 & 0.3163 & 3.162 \\
\hline & & $k_{0}$ & $1.938 \mathrm{E} 33$ & -4.760 & 2440.01 & 0.5013 & 1.995 \\
\hline & & Troe & \multicolumn{3}{|c|}{$A=0.783, T_{3}=74.0, T_{1}=2941.0, T_{2}=6964.0$} & 0.7943 & 1.259 \\
\hline 19 & $\mathrm{H}+\mathrm{OH}+\mathrm{M} \rightleftharpoons \mathrm{H}_{2} \mathrm{O}+\mathrm{M}$ & & $4.00 \mathrm{E} 22$ & -2.000 & 0.00 & 0.2765 & 1.106 \\
\hline 20 & $\mathrm{H}_{2} \mathrm{O}+\mathrm{O} \rightleftharpoons 2 \mathrm{OH}$ & & 7.00E05 & 2.300 & $14,548.28$ & 0.3778 & 2.445 \\
\hline \multirow[t]{3}{*}{21} & $\mathrm{CH}_{3} \mathrm{OH}(+\mathrm{M}) \rightleftharpoons \mathrm{CH}_{3}+\mathrm{OH}(+\mathrm{M})$ & $k_{\infty}$ & $1.90 \mathrm{E} 16$ & 0.000 & $91,729.92$ & 0.5013 & 1.995 \\
\hline & & $k_{0}$ & 2.95E44 & -7.350 & $95,460.09$ & 0.3163 & 3.162 \\
\hline & & Troe & \multicolumn{3}{|c|}{$A=0.414, T_{3}=280.0, T_{1}=5500.0$} & 0.7943 & 1.259 \\
\hline \multirow[t]{3}{*}{22} & $2 \mathrm{CH}_{3}(+\mathrm{M}) \rightleftharpoons \mathrm{C}_{2} \mathrm{H}_{6}(+\mathrm{M})$ & $k_{\infty}$ & $1.81 \mathrm{E} 13$ & 0.000 & 0.00 & 0.5013 & 1.995 \\
\hline & & $k_{0}$ & $1.27 \mathrm{E} 41$ & -7.000 & 2762.91 & 0.5013 & 1.995 \\
\hline & & Troe & \multicolumn{3}{|c|}{$A=0.62, T_{3}=73.0, T_{1}=1200.0$} & 0.7943 & 1.259 \\
\hline 23 & $\mathrm{HCO}+\mathrm{O}_{2} \rightleftharpoons \mathrm{CO}+\mathrm{HO}_{2}$ & & $7.58 \mathrm{E} 12$ & 0.000 & 409.89 & 0.3215 & 1.440 \\
\hline 24 & $\mathrm{CH}_{3}+\mathrm{OH} \rightleftharpoons \mathrm{H}_{2} \mathrm{O}+\mathrm{CH}_{2}^{\star}$ & & $2.36 \mathrm{E} 17$ & -1.200 & 1811 & 0.3506 & 1.440 \\
\hline 25 & $\mathrm{C}_{2} \mathrm{H}_{4}+\mathrm{OH} \rightleftharpoons \mathrm{C}_{2} \mathrm{H}_{3}+\mathrm{H}_{2} \mathrm{O}$ & & 5.53E05 & 2.300 & 2963.67 & 0.1720 & 2.351 \\
\hline 26 & $\mathrm{CH}_{3}+\mathrm{O}_{2} \rightleftharpoons \mathrm{CH}_{3} \mathrm{O}+\mathrm{O}$ & & $1.10 \mathrm{E} 13$ & 0.000 & $27,820.03$ & 0.0613 & 2.311 \\
\hline 27 & $\mathrm{O}_{2}+\mathrm{CH}_{2}^{\star} \rightleftharpoons \mathrm{CO}+\mathrm{H}+\mathrm{OH}$ & & $3.13 \mathrm{E} 13$ & 0.000 & 0.00 & 0.3164 & 3.164 \\
\hline 28 & $\mathrm{HNO}+\mathrm{NO} \rightleftharpoons \mathrm{N}_{2} \mathrm{O}+\mathrm{OH}$ & & $2.00 \mathrm{E} 12$ & 0.000 & 26,000 & 0.3162 & 3.162 \\
\hline 29 & $\mathrm{O}_{2}+\mathrm{CH}_{2} \rightleftharpoons \mathrm{CO}_{2}+\mathrm{H}_{2}$ & & $2.23 \mathrm{E} 12$ & 0.000 & 1491.4 & 0.2548 & 7.323 \\
\hline 30 & $\mathrm{CH}_{4}+\mathrm{O}_{2} \rightleftharpoons \mathrm{CH}_{3}+\mathrm{HO}_{2}$ & & $3.98 \mathrm{E} 13$ & 0.000 & $56,890.54$ & 0.7812 & 25.82 \\
\hline
\end{tabular}

